\title{
Editorial
}

\section{Sinking and swimming at the Yeosu expo: Public diplomacy and nation branding in South Korea, 2012}

Place Branding and Public Diplomacy (2012) 8, 249-255. doi:10.1057/pb.2012.23

As I have argued in this space before, if there is an institution in which the arts of public diplomacy and nation branding converge, it is the international exposition. Although this year's expo - held in Yeosu, South Korea in the summer of 2012 on the theme of The Living Ocean and Coast - was always going to be a shadow of the spectacular Shanghai Expo of 2010, it still promised to illuminate contemporary practices in the field. With this in mind, I decamped to Yeosu this past July to visit the new crop of national pavilions and talk to some of the teams behind them and some of the hardy souls in the Bureau International des Expositions who coordinate them.

The roots of the Yeosu Expo lay partly in South Korean public diplomacy. The country's long campaign of national outreach had already produced an Olympic games (Seoul, 1988), a new government cultural diplomacy agency: the Korea Foundation (1992), an earlier expo (Tajeon, 1993) and a Soccer World Cup (co-hosted with Japan in 2002), so a plan to host a new expo was hardly surprising. What was surprising was the decision to propose Yeosu as the location. Yeosu is a small port city of 300000 or so people in the center of the Korean peninsula's southern coast. It is home to an oil refinery and was in need of a developmental boost. Although significant enough to have an airport, planes only travel to two destinations: Seoul and Jeju Island, a favorite Korean vacation spot, some hundred miles to the south. Yet, the plan to redevelop a brown field site harbor for the expo had its charms and Yeosu won the right to host in 2007 over bids from Tangier, Morocco and Wrocław, Poland. The bid coincided with a spike of government interest in ideas of nation branding and a growing attention to Korean popular culture - the Korean Wave - in East Asia and beyond. The fair presented an ideal opportunity to further cement Korea's standing in the region. The plan for the expo included an internationally relevant ecological theme of ocean preservation, showing Korea as a leader in a vital area to the future of the planet. The concept included a corporate zone to showcase the great Korean corporations (LG, Hyundai, Samsung and so forth); entertainment spaces; themed buildings including a massive aquarium and a pavilion on the ocean; and coastal best practices, all housed in cutting edge architecture. International participants would be located in a central multistory mall, in units of various sizes, which could be adapted according to the specifications of the country concerned. The mall's central 
aisle would be covered by a vast digital roof the expo digital gallery - which would carry images of life under the sea. The whole complex would, after the closure of the expo, be repurposed as a resort area. ${ }^{1}$

The Yeosu plan was not without risk. There was a chance that so soon after the Shanghai expo, foreign governments would prove shy of Yeosu, but participation was impressive regardless. Six months before the opening, the organizers were able to claim that over 100 countries were coming. Notable stay-aways included Britain, which with the Olympics, diamond jubilee of Elizabeth II and 'Great' campaign had no need for another international platform, and Saudi Arabia, which had run the most popular pavilion at the Shanghai Expo and dropped out of Yeosu at the last minute. Canada - a regular at other expos and a famous host from 1967 - not only withdrew from the expo and Milan in 2015, but also cancelled its membership of the BIE, turning its back on the whole idea of the expo. Other absentees included South Africa and Brazil, the former exhausted from recent duty as a World Cup host and the latter (despite plans to bid for the 2020 expo) keeping powder dry for the Olympics in 2016. However, the others committed and delivered. Thirty or so booked top-tier pavilions, including France, Russia and neighbors China and Japan. Other prominent participants were former recent expo hosts - Germany and Spain - upcoming hosts like Italy and states with active bids to host an expo, including Kazakhstan, UAE and Turkey. Lower-budget participants agreed to take space in multinational regional pavilions.

Given the controversy around the organization of the US presence at Shanghai, America's performance at Yeosu was of special interest. As in Shanghai, the US pavilion was based around a series of films. There was a formal welcome projected onto a curtain of water, featuring Secretary of State Hillary Clinton, President Obama, who emphasized his personal connection to the ocean flowing from his childhood in Hawaii, and pavilion's guiding light: Philippe Cousteau Jr., the charismatic eco activist and grandson of the French scuba pioneer Jacques Cousteau. Obama's appearance was generally appreciated as few pavilions exhibited this kind of presidential welcome (the other example of Kazakhstan). The pavilion's main film showed the connection to the ocean of individual Americans of all races, regions, ages, genders and abilities/disabilities. As the film cut from one person to another, their refrain was 'This is MY ocean', which the European visitors felt suggested American ownership, but which was felicitously translated for Koreans as 'This is MY link to the ocean.' After a middle section showing the contemporary dangers from the ocean and to the ocean's wildlife, the film the message shifted to 'This is OUR ocean' and an invitation to the audience to join in a partnership to secure the ocean for the future. The pavilion took great care to select and deploy a first rate team of bilingual guides who represented a diverse range of Americans, including Korean-Americans revisiting their parents' and grandparents' homeland, leveraging a Diaspora link. While the guides weren't quite the sensation they had been in Shangahi in a society more used to meeting Americans, their contribution was immense. The visitor experience matched that of the US pavilion in Shanghai, but at a fraction of the cost $(\$ 10$ million against $\$ 60$ million). Yet, the achievement of Yeosu cannot wholly be divorced from the experience of the US pavilion in Shanghai. Money saved from the Shanghai budget (about $\$ 2$ million) provided the seed money essential for the Yeosu pavilion, and it took the determination of Assistant Secretary of State Kurt Campbell to see participation to its finish. Staff noted that Campbell shed a tear when he first saw the guides welcoming the Korean public to the pavilion he had worked hard to build. The pavilion scored with the locals, as did the range of practical community projects associated with the pavilion, which included staff volunteering at a local high school and quietly helping out at a refugee camp for North Koreans. It should have been hailed as 
a success, but sadly no one in the media back home noticed. Controversy and negativity make much better readings. ${ }^{2}$

Of the other big budget players the German pavilion 'Seavolution' made an excellent impression. After an atmospheric film about Germany's coast, the screen opened to reveal a reconstruction of a Baltic beach complete with the iconic Strandkorb (covered beachchairs), which doubled as display units. A range of exhibits on German contributions to ecology and maritime engineering followed before a spectacular final film depicting the future of oceanic exploration. ${ }^{3}$ The Russian pavilion was also of high grade, focusing on that country's contribution to polar exploration with a simulation of the work of an icebreaker, including a view of a vessel powering through the arctic, as seen from the pack ice. ${ }^{4}$ The value of the Russian pavilion was multiplied by excellent guides and the associated gift of a pair of arctic beluga whales to the expo aquarium, and visits from tall ships. Cheerful sailors in blue and white uniforms and broad rimmed caps of the Russian navy were evident within the crowd. As one might have expected, the Chinese and Japanese pavilions were both elaborate and popular with the crowds. China offered a film and allegorical dance performance, while Japan focused on the process of recovery following the Tsunami, with acknowledgement of the aid received from Korea during that crisis. It was an example of the public diplomacy power of saying thank you. Kazakhstan presented an unexpectedly elaborate offering as part of their ultimately successful campaign to bring the 2017 expo to Astana mixing film and folkdance performance.

Of the smaller players Singapore did well, showcasing ecologically sensitive city design under the clever title 'Paradox-ity: City of Contract.' Switzerland offered a technically brilliant pavilion, which won a gold award from the BIE for creative display in a middle-sized pavilion. ${ }^{5}$ It turned on the idea of the future of water being 'in your hands.' In the first section - a dark passage - symbols representing the answers to questions about water were ingeniously projected onto visitor's palms. There was a video encounter with a glacier, an ice chamber featuring an ice core sample, which at its base was older than the country of Korea and an art installation suggesting the movement and flow of water. As visitors left, a plastic cone containing pure water was placed in their hands and each was urged to think about protecting the source of water. ${ }^{6}$ Some countries actually asked the visitors to make a commitment to projecting the maritime environment. Qatar showcased these commitments on a 'pledge wall.'

Israel's pavilion, 'sea of inspiration', was something of a mystery, as the greater part of it was an art installation, but it excited the attention of the numerous Korean Christian fairgoers because of the displays showing biblical sites like the Sea of Galilee. Expo designers do well to imagine play to the likely interests of their audience. The Dutch were able to lean on another Korean religion - football - and hence, an otherwise humdrum pavilion film included an image of Dutch soccer coach Guus Hiddink, who led South Korea to the semifinals of the 2002 world cup, captioned: 'We share our knowledge.' A number of countries sought local relevance by recalling national participation in the Korean War. Turkey included a photograph of a Turkish soldier reaching out to a Korean child in their pavilion, while Thailand included newsreel images of Thai soldiers in a montage of Thai/Korean relations, though it was a little odd to have the scenes introduced by a mechanical mermaid.

Fairs always provide an opportunity to create a branded space in which the visitor can be immersed in positive experiences and/or messages associated with a particular country. The Scandinavians have of late become masters of this. At Yeosu, the Swedes used a mixture of guides and text to communicate key facts about their country; Koreans learned that 46\% of Swedish households are single-person. The text emphasized the value of play in a balanced Swedish life, though the pavilion's design was not especially playful, unlike that of Denmark. 
The Danes cornered the market in playfulness by providing vast supplies of Lego bricks in blue and white to resemble an ocean with foam and inviting guests to unleash their personal brainwave. Other features in the pavilion included a display on wind power where visitors could light a model city by blowing a miniature turbine and a sandwich bar. ${ }^{7}$ Norway offered a high-speed video journey along the country's amazing coastline. Of the neighboring Baltics countries, Lithuania created a visually splendid pavilion based around the country's reputation as the chief source for amber: an amber interior studded with viewing tubes to look down into magnificent amber blocks containing amber blocks, as a lead into an amazing jewelry store. Unfortunately, the Korean public did not buy enough amber and a few weeks into the expo, the store closed, reputedly in order to relocate to New York's 5th Avenue.

Sometimes an expo display can illuminate a country or region at a particular turning point in its history. Given the recent political changes in the Middle East, the content of Arab pavilions had special significance. Egypt's offering was uninspired, perhaps because the display technologies proved unreliable; Tunisia played it safe and focused on its antiquities and folk art, but UAE successfully presented itself as a dynamic society in transition. Besides some excellent static exhibits on wildlife, the core of the UAE pavilion was a film telling the story of a boy who becomes caught up in his marine biologist father's attempt to rescue a sea turtle that has ingested a polythene bag. The supporting cast included real UAE-based scientists: a 'liberated' Arab woman who appeared with her hair uncovered in an eye-catching wetsuit and a rugged westerner, called to the turtle's aid. Of course there were iconic shots of helicopters soaring over the Dubai skyline and the westerner had to be summoned from the middle of the desert where he is enjoying a spot of powered parachuting. The child prays for the animal, but his prayer is not answered. When the creature dies, the child launches an Arab Spring-like peoples' campaign against the use of polythene bags. Even though the story was fictional, it was fascinating to see the Emirates branding themselves as responsive to public opinion and encouraging people in other countries to organize to make a difference. It was a good way to draw attention to the real ban on the use of carrier bags soon to be implemented in the country. ${ }^{8}$

Expos are always a showcase for innovation in display. Yeosu had the usual share of '4D' film and exhibit experiences, sliding screen 'reveals' and magnificent sound systems. Technical innovations ranged from a daily video hookup with an Australian diver on the barrier reef to many countries using state-ofthe-art animation to make their points. Indonesia, China and Japan were especially engaging. Thailand, Turkey, Egypt and Spain were all strong in that regard. Some pavilions made use of their outside walls to communicate messages. Some outside messages were a little bizarre. The exterior of Tunisia's pavilion included a quantity of barbed wire and the legend: 'Don't touch on my Mediterranean Sea.' Many pavilions worked to exploit the opportunity to extend the message of their pavilion through technology. It made excellent sense to offer smartphone content in the homeland of the Samsung Galaxy. Displays included free smart device applications that could be loaded by photographing QRs mounted within exhibits or on signs next to the places where people lined up to enter the pavilions. Some offered competitions to visit their country, others offered bonus content and links to information. There were some clichés. At Shanghai, UAE had scored a hit with a short film based around a cross-generational magical flying journey. Imitators in Yeosu included Algeria and Kazakhstan. Others hit on the same issues - those who visited every pavilion might have become weary of the multiple expressions of concern for the fate of the manatee and all were upstaged by the robot manitee in one of the Korean pavilions.

As in Shanghai, the smallest and poorest countries had the chance to participate in regional group pavilions, presenting stands that 
ranged from creditable small exhibits to lackluster souvenir stands. A number of landlocked countries had to work especially hard to associate themselves with the cause of maritime ecology. Mongolia seemed out of place in the Pacific Ocean pavilion round the corner from the giant sign reading PARADISE. Smaller African participants were divided between the communal Indian Ocean and West Atlantic. Despite its absence of a coastline, Uganda did rather a good job with superior craft products and an interesting display about mountain gorilla sanctuaries. As is traditional at expos, all those present - big or small - had an opportunity to shine on their respective national days. The BIE recognized Gabon and Senegal as having particular merit.

One of the joys of touring an expo is when a pavilion actually works as intended to whet one's appetite to actually visit. For this observer, the new additions to the 'bucket list' were Angola and Uruguay. Angola really scored with warm and welcoming guides, engaging audiovisuals and a terrific restaurant with life music each lunchtime. Uruguay's simple pavilion - decked in the national colors of blue and white - presented an engaging mix of material on the local relationship with the sea that somehow seemed fresh. Conversely, there are always disappointments. Woody Allen famously remarked that $90 \%$ of success is 'showing up.' Unfortunately, some of the pavilions seemed crafted to disprove this maxim. Belgium, Italy and France were, to my mind, below expectations. The Italian pavilion fixated on the great achievements of the age of navigation, which unfortunately had been better represented in the Spanish pavilion. The space included a 'brand Italy' film theater, which was screening a documentary in English without Korean subtitles. Visitors used the room for naps. It was a sad contrast to the Italian achievement in Shanghai and exciting plans for the Milan expo in 2015. France offered an oddly disconnected pavilion displaying a number of their contemporary maritime projects in between such 'fun' exhibits as mechanical fish swimming past submerged models of famous French buildings and a wall decorated with disembodied robotic arms, which 'played' musical instruments every twenty minutes of so. Belgium's pavilion conceived as part of the unsuccessful bid by Liege to host the 2017 expo show - presented a rather cheap-looking display of national icons mounted on a carousel, a waffle stand and video monitor display. One assumes that the economic downturn must have brought a reduction to budgets. Further afield, the underwhelming offerings included two pavilions, which opened late: Nigeria and Mexico. Nigeria used their large space for little more than a sculpture exhibit. Despite an enthusiastic pavilion team, Mexico chose to represent itself purely as a tourist destination, and one in which lighter-skinned Mexicans are apparently served by their darker-skinned compatriots, while indigenous children frolic as extensions of the fauna. An opportunity to reach out to Korea as a partner for conservation or trade was missed. Some nations placed rather too much confidence in the ability of a slogan to reposition a national brand. Neither 'Belgium is fashion' nor 'Pakistan: Land of 180 million smiling faces' is destined for glory.

Some pavilions struck ominous notes. It was alarming that the pavilion of Argentina thought it appropriate to open the country's claim to the sovereignty of the Falkand/Malvinas Islands in what is supposed to be an apolitical context. Similarly, for all the fun of being transported onto the bridge of a Russian ice-breaker, it was a little worrying to see repeated references to the fact that in 2007 the Russian Mir submarine Roosya had placed a Russian flag on the sea bed at the exact point of the geographical north pole. Although the exhibition commentary went on to explain Russia's commitment to multilateral management of the Polar region, the subtext was that Russia had a unique and pre-eminent role in the Arctic past and future, and special claim on the minerals below the Arctic seabed.

One hidden benefit of Yeosu was the camaraderie which developed between the various foreign pavilions. All the exhibiting 
nations had to endure the quirks and rough edges of the venue and the visitors, but more than this the pavilions had to rely on one another from time to time for favors such as taking care of a visiting dignitary and his staff on a short-notice VIP tour. These bonds developed in unexpected places and were an unseen diplomatic bonus. It was also good to see the dividend of previous fairs in the form of a number of foreign volunteers from previous expo cities coming to help Yeosu. They were distributed widely and not restricted to their national pavilions. The volunteer guide contingent from Spain was especially numerous and helpful.

The organizers were pleased with the eventual attendance figures for the expo, which they claimed surpassed the target of eight million. ${ }^{9}$ It is still too early to tell whether national participation was worthwhile; indicators like shifts in tourist numbers or trade will tell their story. Success was not always assured. Alarm bells sounded in the early days, as the crowds initially stayed away. There was little interest in the expo from neighboring countries and while the expo's boosters successfully reached out to Korean audiences to attend, they directed them primarily to the Korean aspects of the expo: the aquarium, the themed pavilions, the corporate zone and the K-pop shows. The organizers-suggested itinerary recommended saving the international pavilions until day 4 of a stay at the fair. The managers of some foreign pavilions were not amused. As numbers picked up, pavilions competed with one another in reporting attendance, though some figures bore little relation to reality and the raw numbers took little account of the amount of time spent in a pavilion or messages absorbed therein. The interim verdict seems that although the expo succeeded in presenting a range of foreign place brands to South Korean audiences, thereby contributing to the globalization of Korea, and promoted a beneficial domestic identification between Korea and a global citizenship, it could not really be considered a success for the export of the South Korean image. Foreign attendance was simply too low.

Whatever the long-term verdict on Yeosu, and despite the withdrawal of the Canadians from the BIE, the future of the expo as a diplomatic form seems secure; many pavilions looked ahead to 2015, 2017 or even the 2020 expo. Those considering their participation in the next round of fairs might care to consider the following seven expo commandments (or should that be pillars of expo wisdom), which seemed to this observer to emerge from the Yeosu experience and match lessons of Shanghai. One: thou shalt be relevant to the audience rather than thy own self obsessions. Two: thou shalt be respectful of the declared theme and not digress into generic displays of folk art. Three: thou shalt seek out multipliers such as online and smart media content and community events, which show a genuine regard for your hosts. Four: thou shalt consider both the inside and outside of the pavilion and the flow of people within and guard against bottlenecks. Five: thou shalt remember the value of sending thy own people to engage foreign audiences face-to-face to face as guides, and a visit from thy monarch or celebrity figurehead is also a great idea. Sixth: thou shalt remember that attention to the environment and sustainability now comprise the international moral compass and strive to identify thy country with their precepts. The seventh commandment - exemplified by Peru at Yeosu - is simple and reflective of the undoubted power of gastrodiplomacy: thou shalt have a great restaurant.

\section{NOTES}

1 For the main expo website see http://eng .expo2012.kr/main.html?mobile_at=Y

2 For the US pavilion site see http://www .pavilion2012.org/

3 For the German pavilion site see http:// expo2012-deutschland.de/en/

4 For the Russian pavilion site see http:// expo2012korea.ru/en/

5 On pavilion prizes see http://www.bie-paris. org/site/en/articles/expo-yeosu-2012/472- 
yeosu-expo-wraps-up-with-82-million-visitors-bie-prizes-announced.html

6 For the Swiss pavilion site see http://www .swisspavilion.ch/en/korea/swiss-pavilionexpo-2012-yeosu.html

7 For the Danish pavilion site see http://www .ebst.dk/expoinfo.english/danish_pavilion_ yeosu

8 For the USE pavilion site see http://www .expo2012uae.com/. For the pavilion video 'The Turtle' see http://www.youtube.com/w atch? $\mathrm{v}=\mathrm{Hu} 1 \mathrm{js} \mathrm{C} 1 \mathrm{tq} 8 \mathrm{Q} \&$ list $=\mathrm{UU} 4-\mathrm{N} 9 \mathrm{CIolO}$ $\mathrm{nZtOjIEldFg} 1$ A\&index $=4 \&$ feature $=$ plcp
9 This claim was not without controversy. The day after the Expo closed an anonymous email circulated among larger pavilion managers, BIE staff and the Korean media detailing evidence of last minute number padding including a video of the young female ticket-takers standing at the turnstiles, tapping tickets on the scanner to drive up the day's total.

Nicholas J. Cull University of Southern California, Los Angeles, CA, USA 